\title{
Earthquake-Tsunami in South Jogjakarta Indonesia: Potential, Simulation Models, and Related Mitigation Efforts
}

\author{
Widjo Kongko and Rahman Hidayat \\ Coastal Dynamics Research Center, the Agency for the Assessment and Application of Technology \\ BPDP BPPT, Jl.Grafika 2 Sekip, Jogjakarta 55281 Indonesia
}

\begin{abstract}
The potential of earthquake-tsunami in South Java is lower than those in South-West of Sumatra. The recent earthquake-tsunami in this area was the "tsunami earthquake" with the relatively slow characteristics of the earthquake and generating greater tsunami. The results of model simulations with limited scenario in South Java showed a significant tsunami affected southern of Jogjakarta's coastal region. To support disaster mitigation and planning of infrastructure development in the southern coastal areas, it is necessary to study the potential earthquake-tsunami disaster and its mitigation efforts using detail and accurate topographicbathymetric data.
\end{abstract}

Keywords: South Java, tsunami earthquake, disaster mitigation and infrastructure development, detail and accurate topographic and bathymetry data

\section{Introduction}

To balance the economic growth in the region between the northern coast and the south coast as well as to face the challenges of traffic problem at north-coast lines of Java island, Government provided programs on the development and improvement of transport infrastructure either land, sea or air transportations on the south coast. The development effort required proper transportation planning and development so that the implementation can be carried out effectively and efficiently.

The challenges include physical condition or hilly topography of southern Java, limited funds for land acquisition and infrastructure development, and the potential disasters that threaten the region. The existing roadway, port, coastal areas and estuaries are disaster-prone areas, such as landslides, sedimentation and erosion due to sea waves, and the earthquake-tsunami disaster.

To support the above programs, it is necessary to study potential earthquake-tsunami disaster and to integrate mitigation efforts in the planning and construction of infrastructure.

\section{Study Area}

The Study area (Figure 1) is situated in the southern coast of Central Java, located in the southern coast of Jogjakarta Special Region (equivalent to provinces), divided from west to east consecutively into three districts, Kulon Progo, Bantul and Gunung Kidul respectively, which stretches along $115 \mathrm{~km}$ laying between

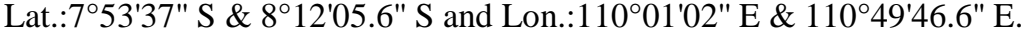

Jogjakarta south coast is characterized by gently sloping sandy beaches in west side, and among which there are some sand dunes. Meanwhile, the eastern part of the region is dominated by steep limestone hills which are difficult to access either by vehicle or human. There are several rivers flow into the South coast Jogjakarta and throughout the year, such as Progo river, Opak river, and the Serang river. In the sloping areas, especially in the Bantul District and Kulon Progo District, Parangtritis beach, Depok beach, Samas beach, and Pandansimo beach (to mention some tourism beach spots) are located, crowded by local and foreign tourists, almost similar with the situation found along the Kuta or Sanur beach in Bali Island.

Prominent infrastructure existing today is Sadeng fishing port (Gunung Kidul District) in eastern side and Tanjung Adikarta port (Kulon Progo District) in the west side. For the regional development of Jogjakarta, especially Jogjakarta's community economic development, both central and local government plan to build transport infrastructure in south coast of Jogjakarta, by the establishment of a new international airport of Jogjakarta (considered as expansion of the existing Adisutjipto International airport) and new road alongside the beach (coastal road) as part of the development plan of Southern Cross Path Road.

\section{Earthquake-Tsunami Potential}

Coastal waters of south of Jogjakarta is categorized as open water (open sea) connected directly with the Indian Ocean. Hence the wave energy towards the coastline is very influential to the dynamics of the beach in the area. Wave energy, besides causing abrasion, also serves as a component of alongshore current generation (longshore current) that may cause sedimentation in certain areas [1]. 
South Java subduction zones have lower seismic activity compared to those in Sumatra [16]. Based on the historical data, intense earthquake happened in South Java subduction area in period of 1977-2007 (Figure 1) with $\mathrm{M}>5$ and 400 events were categorized as shallow $(<40 \mathrm{~km})$. In this period, two earthquakes occurred in Banyuwangi (East Java) in 1994 and in Pangandaran (West Java) in 2006 had significant magnitude and caused a tsunami with an average height of 5-8 $\mathrm{m}$ and killed more than 800 people [2] [3][4][5]. Meanwhile, based on USGS data, in the period of 1978-2008, there have been large earthquakes $(M>6.5)$ by 20 times where 2 of them caused tsunami [6]. Thus, south Java area, on average, has 1 to 10 times of medium-large earthquake potential every year with its potential to cause a tsunami.

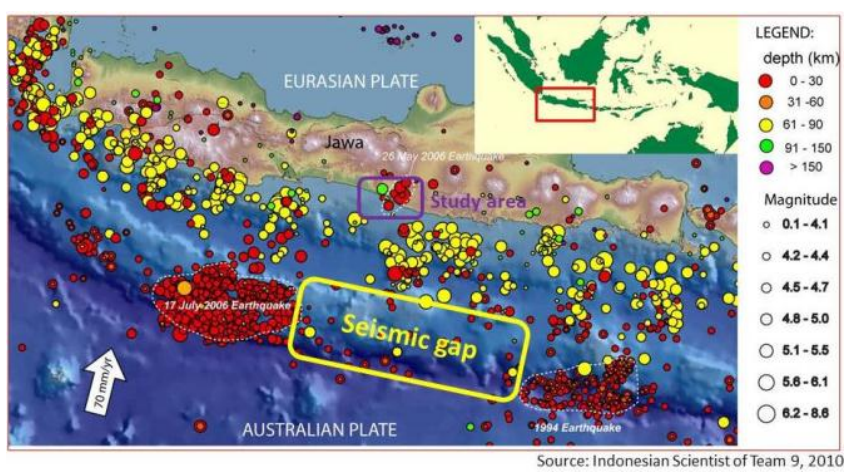

Figure 1 Historical earthquake and the "seismic gap"

Figure 1 shows clear visible void seismic activity ("seismic gap" - a yellow box) between $109^{\circ}$ and $112^{\circ}$ East Longitude. This phenomenon remains questioned. In addition, historical data and recent studies of earthquake and tsunami occurred in Pangandaran in 2006 show "tsunami earthquake" [7][8]. Earthquaketsunami is slow process, occurring in the shallow area near the trough of the ocean and has potential to cause bigger tsunami (2-3 times) compared to other general earthquake and tsunami [9][10]. Since that, people perceive "tsunami earthquake" shocks are relatively small make it ignored by the people in the coastal areas resulting in many casualties as happened in the earthquake-tsunami in Pangandaran (2006) and Mentawai (2010) in west coast of Sumatera Island [3][11].

\section{Simulation Model of South Java Tsunami}

Up to now, science and technology has not been able to predict when, where, and how big the magnitude of the earthquake is going to happen. Therefore, to assess the possibility of earthquake-tsunami and its impacts in the future numerical simulation is used with several approaches and scenarios. Through this simulation the potential inundation area and the propagation time at study area can then be estimated.

\subsection{Earthquake-tsunami Scenarios}

Simulation of the earthquake-tsunami in South Java uses a single source generation scenario. The worst possible condition of "tsunami earthquake" is predicted based on the historical data of epicenter and earthquake parameters such as depth and focal mechanism. The earthquake is assumed to occur in a "megathrust" in the south of Java with a magnitude M 8.2. Dimension of fault based on empirical calculations [12][18] with the details of earthquake parameters is shown in Table 1.

Table 1 Earthquake parameters and fault dimension

\begin{tabular}{|c|c|c|c|c|c|c|c|c|}
\hline \multicolumn{2}{|c|}{ epicenter } & L & W & \multicolumn{3}{c|}{ Angle Parameters } & Du & Depth \\
\hline $\mathrm{X}$ & $\mathrm{y}$ & $(\mathrm{km})$ & $(\mathrm{km})$ & Strike & Dip & Slip & $(\mathrm{m})$ & $(\mathrm{km})$ \\
\hline 110.0277 & -9.74115 & 300 & 150 & 280 & 10 & 90 & 4.46 & 15 \\
\hline
\end{tabular}

Notes: $\mathrm{x}$ refers to Latitude; y refers to Longitude; L=Length; W=Width; Angle parameter is degree; Du=vertical displacement

\subsection{Topographic-bathymetric Data}

General Bathymetric Chart of the Oceans (GEBCO) 2008 for deep water (more than -1000 m) and detail Navy Chart for shallow water were used for bathymetric data with respective resolution 30" and 3" arcsecond. Meanwhile, Shuttle Radar Topography Mission (SRTM) data with a resolution of 1" arc-seconds as corrected with the ground survey was used for topographic data. Most of these data are available on the internet and in the repository of related research projects. Besides the above-mentioned data, it is still difficult to obtain data with better resolution, such as ITERMAP / LiDAR at the location of the study area. 
Earthquake-Tsunami in South Jogjakarta Indonesia: Potential, Simulation Models, and...

\subsection{Numerical Model Setup}

Numerical model used in this study was TUNAMI which is 2-dimensional models based on non-linear shallow wave equations with finite difference method solution. This model has been well calibrated and used as the standard by IOC-UNESCO and has been being used to study the tsunami in over 22 countries [13][14]. In this study a 5 stages nested grid models used with spatial dimensions (m) and time (s): 1851 (2), 617 (1), 206 (0.6), 69 (0.4), and $23(0.2)$ respectively with simulation time of 5,400 seconds (1.5 hours). Manning roughness, $\mathrm{n}=0.025$ used for shallow areas and land use representing the land cover of an open natural sand beach, as well as near shore areas [19].

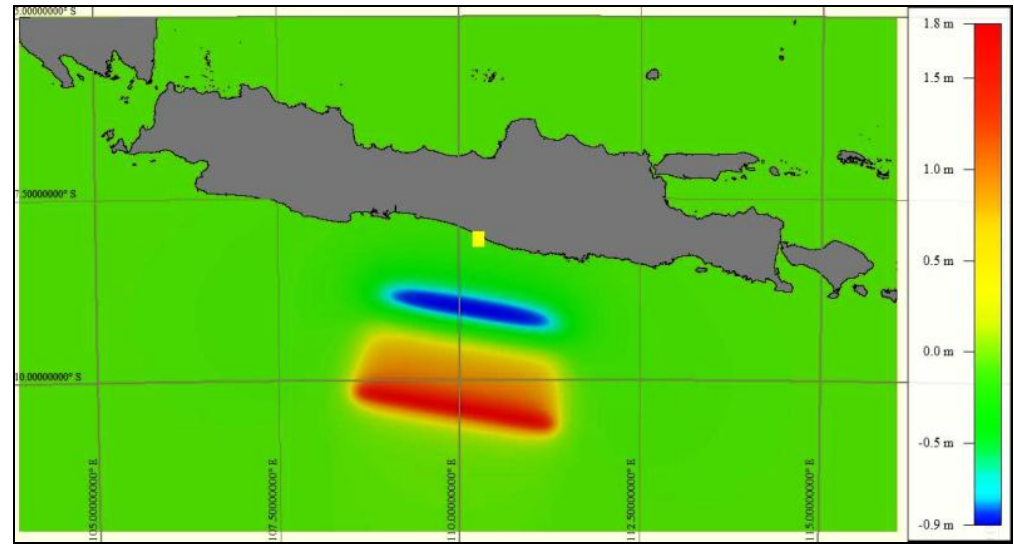

Figure 2. Source of "tsunami earthquake" from M 8.2 earthquake according to the scenario in Table 1

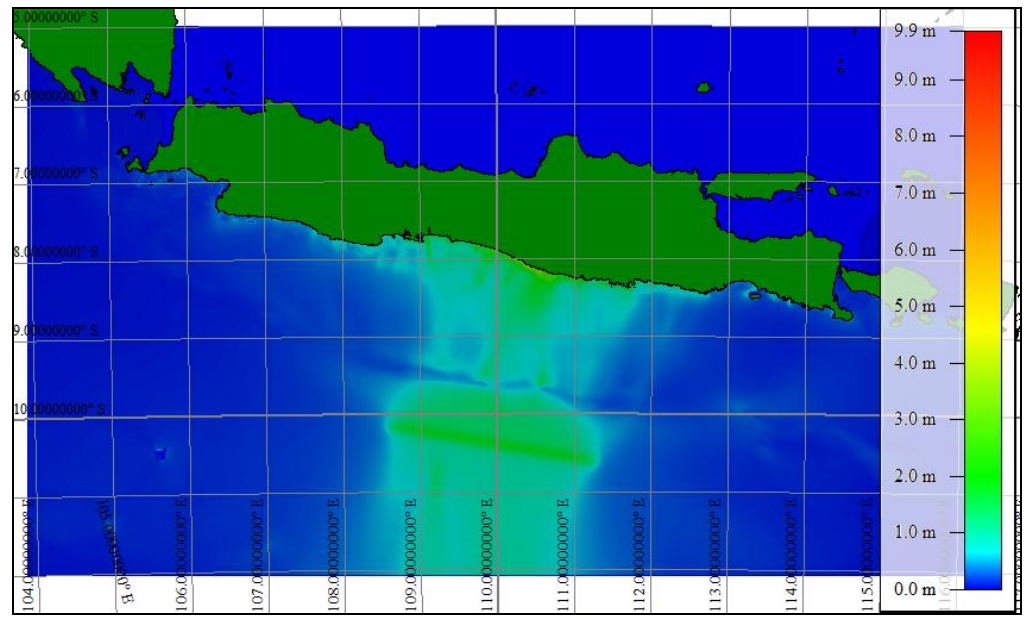

Figure 3. Maximum height of the tsunami from $\sim$ M 8.2 earthquake, with a 1.5-hour simulation

\subsection{Simulation Results}

The simulation results consist of: tsunami height at source, the maximum tsunami height, and the tsunami inundation in the study area, and propagation time. The tsunami height at source based on a scenario as stated in Table 1 is in the range from $-0.9 \mathrm{~m}$ up to $1.8 \mathrm{~m}$ as shown in Figure 2. For simulation time of 5,400 seconds (1.5 hours), the maximum tsunami height is $\sim 9.9 \mathrm{~m}$ as shown in Figure 3. In addition, inundated area of the south coast of Jogjakarta, particularly Bantul and Kulon Progo District, approximately $20 \mathrm{~km}^{2}$ (2,000 Ha). Meanwhile, the maximum penetration reach up to $2 \mathrm{~km}$ upward and flow-depth $\sim 6 \mathrm{~m}$. Worst affected area is the area around the mouth of the Progo and Opak river eastward up to the Parangtritis beach, with an inundated area of approximately $13 \mathrm{~km}^{2}(1,300 \mathrm{Ha})$.

For the purpose of observation and control of wave arrival time at the coastline, 7 virtual points, i.e. Trisik beach, Pandansimo1 beach, Pandansimo2 beach, Samas beach, Depok beach, Parangtritis beach, and Parangendok beach were simulated. These points used were the ones close to the coast with water depth varying from -2 to $-7 \mathrm{~m}$. The first tsunami wave arrived 33 to 40 minutes after the earthquake with a wave height $\sim 2 \mathrm{~m}$, depend on the location. Arrival time of tsunami propagation and tsunami inundation affected area of Bantul District, based on the scenario in Table 1 is shown in Figure 4. 


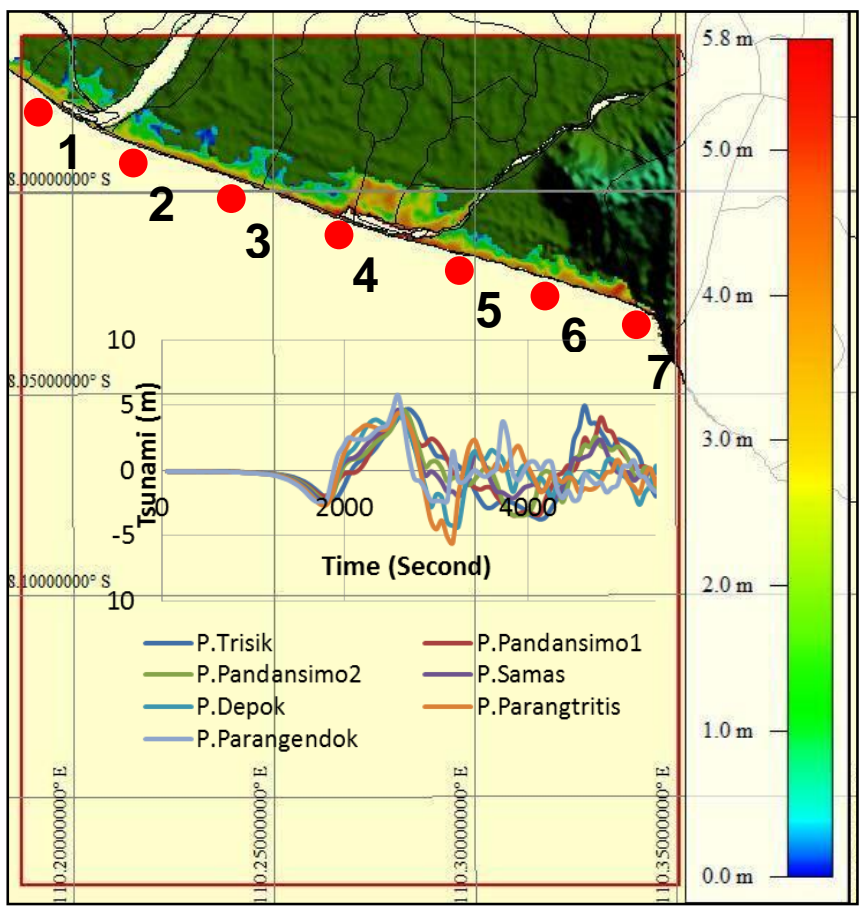

Figure 4. Inundation depth $\&$ its arrival time affected from $\sim$ M 8.2 earthquake in the district of Bantul

\section{Adaptation and Mitigation Efforts}

In general, mitigation is defined as the effort or action to reduce the impact of a hazard before it occurs [17]. For tsunami disaster mitigation, it is broadly divided into two categories namely natural and artificial measures. Natural measures include coastal vegetation plantation, preservation and protection of beaches and coral reefs, while the artificial measures include construction of breakwaters, seawall and concept adoption of adaptation by the development of elevated coastal infrastructure. The elevated infrastructures means the arrival tsunami wave will not reach the infrastructure or at least the infrastructure will be strong enough and safe when facing tsunami.

Based on the experiences from several post-tsunami observation and lesson learnt from the most recent tsunami events, namely the Mentawai tsunami (2010) and Japan tsunami (2011), it is convinced there is no "single solution" to effectively reduce the impact of the tsunami. Comprehensive approach involving various aspects should be considered. Public awareness and knowledge about the potential disaster, the uniqueness of local physical morphology in each region, as well as local values evolved from generation to generation are significant factors for the success of tsunami disaster mitigation program supported by policy makers at the local level.

\section{Conclusion}

Although potential of tsunami in southern Java Island is lower than South-West Sumatra Island, but historical data shows the earthquake-tsunami events in the southern part of Java Island is considered high. If an earthquake's epicenter is located near the Java trough with a shallow depth, potentially "tsunami earthquake" will happen, with relatively slow shaking but higher tsunamis in coastal areas. Simulation models done for several points in the southern coast of Jogjakarta area showed that an earthquake with magnitude $\sim$ M 8.2 caused a tsunami height $\sim 6 \mathrm{~m}$ and its penetration up to $\sim 2 \mathrm{~km}$ inland with inundated area of approximately 20 $\mathrm{km}^{2}$. Tsunami arrival time was ranging from 33 to 40 minutes after the earthquake. By considering that the data used in this study was only in a medium to coarse resolution, it is necessary to study the potential earthquaketsunami disaster and its mitigation efforts using detail and accurate topographic-bathymetric data and by considering several scenarios / multi-scenario for the design of infrastructure planning in coastal areas and predictions for evacuation planning purposes.

\section{Acknowledgment}

The author would like to thank the German-Indonesian Tsunami Early Warning System Project (GITEWS), the Australia-Indonesia for Disaster Reduction (AIFDR), and Indonesian Geospatial Information Agency (BIG) for the support of data used in the study area of south Java. 


\section{References}

[1] Bird, E.C.F. \& Ongkosongo, O.S.R., 1980, Environmental Changes on the Coast of Indonesia, The United Nations University, printed in Japan.

[2] Fritz, H., Kongko, W., Moore, A., McAdoo, B., Goff, J., Harbitz, C., Uslu, B., Kalligeris, N., Suteja, D., Kalsum, K., Titov, V., Gusman, A., Latief, H., Santoso, E., Sujoko, S., Djulkarnaen, D., Sunendar, H. \& Synolakis, C., 2007. Extreme run-up from the 17 July 2006 Java Tsunami. Geophysical Research Letters, 34(L12602), pp.1-5.

[3] Abidin, H.Z., Andreas, H., Kao, T., Ito, T., Meilano, I., Kimata, F., Natawidjaya, D.H. \& Harjono, H., 2009. Crustal deformation studies in Java (Indonesia) using GPS. Journal of Earthquake and Tsunami, 3(2), pp.77-88.

[4] Kongko, W., Suranto, S., Chaeroni, C., Aprijanto, A., Zikra, Z. \& Sujantoko, S., 2006. Rapid Survey on Java Tsunami 17 July 2006. Available at: http://ioc3.unesco.org/itic/files/tsunami-Java170706_e.pdf.

[5] ITDB/WLD, 2007. Integrated Tsunami Database for the World Ocean, ver.6.52 of Dec.31 2007, Tsunami Lab. ICMMG SD RAS, Novosibirsk, Russia.

[6] USGS, 2010. Source Parameters of Earthquake Mw 6.5 above at Java Subduction Zone. Available at: http://earthquake.usgs.gov/earthquakes/eqarchives/sopar/.

[7] Ammon, C., Kanamori, H., Lay, T. \& Velasco, A., 2006. The 17 July 2006 Java Tsunami Earthquake. Geophysical Research Letters, 33(L24308), pp.1-5.

[8] Kanamori, H., 1972. Mechanism of Tsunami Earthquakes. Physics of the Earth and Planetary Interiors, 6(5), pp.346-359.

[9] Hanifa, R.N., Meilano, I., Sagiya, S., Kimata, F. \& Abidin, H.Z., 2007. Numerical Modeling of the 2006 Java Tsunami Earthquake. Advances in Geosciences, 13, pp.231-248.

[10] Kongko, W. \& Schlurmann, T., 2011. The Java Tsunami Model: Using Highly-Resolved Data to Model the Past Event and To Estimate the Future Hazard Proceedings of the International Conference on Coastal Engineering, No. 32(2010), Shanghai, China. Paper: management.26. Retrieved from http://journals.tdl.org/ICCE/.

[11] Newman, A.; Hayes, G.; Wei, Y. \& Convers, J., 2011. The 25 October 2010 Mentawai tsunami earthquake, from real-time discriminants, finite-fault rupture, and tsunami excitation. Geophysical Research Letters, 38, 1-7.

[12] Papazachos, B. C., Scordilis, E. M., Panagiotopoulos, D. G., Karakaisis, G. F., 2004. Global relations between seismic fault parameters and moment magnitude of earthquakes. Tenth Congress Hellenic Geol Soc, XXXVI, pp.539-540.

[13] Imamura, F., Yalciner, A.C. \& Ozyurt, G., 2006. Tsunami Modeling Manual, Disaster Control Research Center, Tohoku University, Sendai, Japan.

[14] Shuto, N. \& Fujima, K., 2009. A short history of tsunami research and countermeasures in Japan. Proceedings of the Japan Academy Series B: Physical and Biological Sciences, 85(8), pp.267-275.

[15] Newcomb, K.R. \& McCann, W.R., 1987. Seismic History and Seismotectonic of the Sunda Arc. Journal of Geophysical Research, 92(No. B1), pp.421-439.

[16] Coburn, A.W., Spence, R.J.S., and Pomonis, A., 1994. Disaster Mitigation. Cambridge Architectural Research Limited, Second edition. UNDP Disaster Management Training Program.

[17] Wells, D.L. \& Coppersmith, K.J., 1994. New empirical relationships among magnitude, rupture length, rupture width, rupture area, and surface displacement. Bulletin - Seismological Society of America, 84(4), pp.974-1002.

[18] Kongko, W., 2012. Mitteilungen Heft 99: South Java Tsunami Model Using Resolved Data Tsunamigenic Sources. Doctoral Dissertation at Franzius Institut, Leibniz Universitaet Hannover Germany.

[19] Imamura, F., Bernard, E. N. \& Robinson, A., 2009. (Eds.) Tsunami Modeling: Calculating Inundation and Hazard Maps. The Sea, the President and Fellows of Harvard College, 321-329. 